\title{
A Framework to Study Level of Comfort between Employees of Local and Foreign Cultures in Multinational Firms
}

\author{
Vijesh Jain ${ }^{1} \&$ Rahul Singh ${ }^{2}$ \\ ${ }^{1}$ Institute of Technology \& Science, Mohan Nagar, Ghaziabad, Uttar Pradesh, India \\ ${ }^{2}$ Birla Institute of Management Technology, Knowledge Park- II Greater Noida, National Capital Region, India \\ Correspondence: Vijesh Jain, Institute of Technology \& Science, Mohan Nagar, Ghaziabad, Uttar Pradesh \\ 201007, India. Tel: 91-120-417-4900. E-mail: vijeshjain@its.edu.in
}

\author{
Received: August 6, 2012 Accepted: January 4, 2013 Online Published: January 25, 2013 \\ doi:10.5539/ijbm.v8n4p104 URL: http://dx.doi.org/10.5539/ijbm.v8n4p104
}

\begin{abstract}
Geert Hofstede studied the cultural dimension in multinational firms which play significant role in the professional conduct of employees. Fifth dimension was supplemented on a cross cultural study of Chinese Confucius behavior. In the changing global cross cultural conduct at work place, the firms are facing more challenges than ever before in forming and performing in multi-location and multi-national teams. This study attempts to read the variables to build a framework which measures the Level of Comfort (LoC) between local culture and foreign culture in the multinational firms. The framework developed is also tested on a pilot study with 200 respondents from 10 countries. Results show that Level of Comfort can be measured through a structured questionnaire and also that this level of comfort vary among countries included in the study.
\end{abstract}

Keywords: cultural diversity, comfort with foreign cultures, cross cultural management, managing multi-cultural work force

\section{Introduction}

Comfort of local cultures with foreign cultures has become an important area to understand for effectively managing culturally diverse workforce at MNEs. Estimating the level of comfort of the local cultures with colleagues from alien cultures is a qualitative attribute that can be conveniently assessed by the use of a cross cultural questionnaire. However there are no available qualified research on the structure and content of a questionnaire which can truly gauge the level of comfort of local cultures with foreign cultures especially in a multinational work place setting. Therefore a need is felt to propose a suitable questionnaire for addressing the need to understand the dynamics of comfort of the local cultures with foreign cultures.

Though questionnaires are the most widely used tools especially in large surveys due to the low cost and their ease to apply, however, are subjected to recall bias, thus validation studies should be conducted in order to determine their validity and reliability.

The aim of this research study is to propose the contents, structure, validation and reliability of the questionnaire for estimating the level of comfort of the local cultures with foreign cultures in cross cultural communication in multinational companies.

\section{Literature Review}

A small number of researches have been done referring to enquiry of the level of comfort of local cultures with foreign cultures. And therefore a 'gold standard' questionnaire which can effectively record such level is not available. However a few attempts to enquire into similar phenomenon are referred below

\subsection{Culture and Cultural Comfort}

Culture has been defined in several ways. There are literally hundreds of different definitions of culture as writers have attempted to provide the all-encompassing definitions of this most debated concept. Undoubtedly culture consists of language, ideas, beliefs, customs, taboos, codes, institutions, tools, techniques, works of art, rituals, ceremonies and symbols among others. It has played an important role in human evolution, allowing humans to adapt to the environment to their own liking rather than depend exclusively on natural selection to achieve adaptive success. Every human society has its own particular culture, or socio-cultural system. (Adapted 
from source: Encyclopedia Britannica)

In General culture can be seen as consisting of predominantly three tangible and intangible elements:

- Values - Values are ideas that tell what in life is considered important than others.

- Norms - Norms consists of expectations of how people would behave in different situations.

- Artifacts - It refer to things or material signifying a particular culture. Artifacts reflect the culture's values and norms but are tangible and created by humans.

Engel, Blackwell and Miniard (1995) saw culture as "the values, ideas, attitudes, and other meaningful symbols that help individuals communicate, interpret, and evaluate as members of society". Trompenaars (1994) suggests that a useful way to distinguish among cultures is to look at whether they have a particular type of orientation (affective or neutral). Members of affect-oriented cultures tend to indicate free behavior with respect to their emotional expression while taking important decisions. On the other side, neutral oriented people take on a more informed and rational approach to decision making. According to Hofstede (1980), culture is "the collective programming of the mind which distinguishes the members of one human group from another". Huntington $(1993,1996)$ observed that religious traditions are the foundation of culture. He divided the world into several cultural zones-Western Christianity, Orthodox world, Islamic world, Confucian, Japanese, Hindu, African, and Latin American. Another approach to understanding culture, proposed by Hall (1976), postulated the notion of High and Low Cultural Context. This perspective suggests that high context people are quite effective in the familiar environment, but may find themselves out of place when placed in an unfamiliar environment. On the other hand, low context people may be quite effective in new or unfamiliar environment. Additionally, High Context cultures like those from Asia and South America (Adair 2003) tend to rely more on non-verbal communication and are similar in characteristics to the collective cultures (Hofstede 1991). Low Context cultures, like those from those from USA, Canada, and some of the European countries from western block (Adair 2003), tend to rely on explicit communication and indicates characteristics of individualistic cultures (Hofstede 1991).

Irrespective of the way culture is defined, differences in various elements of culture, e.g., language, social structure, religions, ways and standards of living, values, etc., result in cultural distance and this distance is greater when two cultures are very different (Triandis 1994). An important manifestation of this cultural distance is how one culture perceives behavior of other cultures. If cultural distance is large, possibly people from one country, while visiting another country or settling for job, may find it uncomfortable to interact with people of the host country or vice versa (Hall 1976). Triandis (1994) suggests that most of us are having ethnocentric approach. We therefore tend to view our own behavioral norms as correct and those of others as not so correct. This suggests that when people from different cultural backgrounds meet each other, it may create a sense of discomfort among the participants due to perceived differences in behavioral norms. This level of comfort during inter-personal communication with people of the host country is likely to be even lesser in an environment that is not too familiar to the visitor or an immigrant more so for the immigrants or visitors from low context cultures. It has even been suggested that in certain cases of extreme discomfort of this type, global conflicts can even occur (Triandis 2000). This view has been supported by the discussions and research involving the high-low context dichotomy (Hall 1976). Literature dealing with immigration and expatriate managers, and acculturation (De Cieri, Dowling, and Taylor 1991; Manev and Stevenson 2001; Oh, Koeske and Sales 2002; Valentine 2001), also discusses similar phenomenon. It is suggested that if the cultural distance is less, then the visitor is likely to feel more comfortable with the host culture. This discomfort may increase due to differences in languages, beliefs, attitudes etc.

\subsection{One of the Other Proposed Questionnaires Related to Cultural Comfort}

A useful questionnaire was proposed in a research on 'Attitude change after taking a Virtual Global Understanding Course' (Chia, Rosina C. et al, 2009). In this research, a virtual collaborative classroom was formed at East Carolina University (ECU), using videoconference technology via regular internet to bring students from 18 different countries, 2 at a time, to the ECU classroom to learn about each other's culture. Students from two countries were partnered one on one. They met for 4-5 weeks, and subsequently submitted a joint paper. Then the same process was repeated for two other countries. Lectures and student discussions were managed with pre-determined topics and questions. Classes were conducted in English and reading assignments were placed on the website. Familiarity with technology, knowledge in cultural understanding and attitude change were assessed. After taking this course, all students stated their comfort level in working with, and their desire to interact with, culturally different others grew stronger and their xenophobia and isolationist attitudes decreased. The questionnaire which was used to record the comfort level of participants included questions 
related to topics like stereotype, xenophobia, isolationalism, disinterest in knowing about culturally different others, lack of desire to interact with other cultures, comfort with culturally different others and similar topics. This research questionnaire was somewhat close to estimation of comfort level between diverse cultures but was not exhaustive.

\subsection{Cross-Cultural Interaction Comfort and Service Evaluation}

Another notable research related to cross cultural comfort is 'Cross-Cultural Interaction Comfort and Service Evaluation' (Paswan, Audhesh K. et al, 2005). This study empirically investigates the notion of being comfortable with social interaction in a foreign country (interaction comfort) and its impact on how service quality is evaluated. In addition, two of the antecedents of this interaction comfort are also investigated. The results indicate that the home country social class of the respondents is positively associated with interaction comfort. In addition, similarities or differences between one's home and one's host country during travel also influences this cross cultural interaction comfort. The results also indicate that visitors high on interaction comfort are more satisfied with the service offered the host country and are willing to advocate it to others back home. Apart from some interesting research implications, the findings have several managerial ones, especially in the context of services aimed at the international market.

\section{Research Methodology}

A theoretical structure of the questionnaire was arrived at with the help of 100 volunteers using Delphi technique. The volunteers consisted of cross cultural experts and students of cross cultural courses. The volunteers were grouped in 10 groups. The Delphi sessions were performed in 2 stages.

\section{Stage 1 - Identification of factors (Scales)}

Each group was asked to identify most important factors which are likely to explain the difference among cultures which describe the level of their comfort with foreign cultures. Each group was asked to identify around 15 such factors which explain the objective of the questionnaire along with their explanation of reasons of choices. The group recommendations were read out to all the groups anonymously along with the reason of the choice of the factors and how they explain the phenomenon of the research enquiry. The groups were then asked to modify their choice of factors. In around 10 rounds each group unanimously came out with a common set of 13 factors (components) (2 conditional factors and 11 general factors).

Stage 2 - Identification of questions, as items of Sub - scales (components / factors)

In stage 2, each group was asked to identify a set of most appropriate questions, which represented the identified CFC factors. Each group was also asked to share the reasons of their choice. After each round the results of each group were anonymously read out to all volunteer groups along with the reasons of choice of questions by each group. The groups were then asked to rethink on their choices after every round. In around 12 rounds, each groups agreed on a selected set of questions which represented each identified factors.

The theoretical structure which came out of the above 2 stages of Delphi sessions looked similar to the structure as given in table 1 .

In the next step the above model was retested empirically through applying the above proposed questionnaire to a random sample of $200 \mathrm{MNC}$ employees from more than 10 regions.

Table 1. Proposed CFC questionnaire, suggested by Delphi sessions

\begin{tabular}{|c|c|}
\hline PART 1 (General Sub - scales) & Full Question \\
\hline \multicolumn{2}{|l|}{$\begin{array}{l}\text { SS1: Seeing Benefits in Cross } \\
\text { Cultures }\end{array}$} \\
\hline $\begin{array}{l}\text { Q1: Cross cultural interaction should be } \\
\text { encouraged }\end{array}$ & $\begin{array}{l}\text { Interacting with people from different countries should be encouraged } \\
\text { because it will help us improve our own values and beliefs }\end{array}$ \\
\hline Q2: Important to learn other cultures & I think it is important to learn more about other cultures \\
\hline Q3: Immigrants add value & $\begin{array}{l}\text { I consider foreign immigration as a value added our country's } \\
\text { economy }\end{array}$ \\
\hline $\begin{array}{l}\text { Q4: Like to know differences to build } \\
\text { friendship }\end{array}$ & $\begin{array}{l}\text { Knowing how a person differs from me may help me build our } \\
\text { friendship }\end{array}$ \\
\hline
\end{tabular}


Q5: like to see foreigners coming to my I would like seeing people from other countries come to my country country

Q6: I find other cultures are similar to us

Q7: Learn from other cultures

\section{SS2: Desire for Socializing with foreigners}

Q8: Like to visit a foreigner

Q9: Good feeling to meet a foreigner

Q10: New learning from visiting a foreigner

Q11: Enjoy foreign food

Q12: Fun to learn about foreigners

Q13: Comfortable with foreigners

Q14: Listen to foreign music

\section{SS3: Effect of Patriotism}

Q15: Nothing like my culture represent more values and ethics

Q16: My culture do not need better recognition

Q17: All cultures have same status

Q18: Not like Immigrants getting better salary than us

\section{SS4: Effect of Personal Comfort}

Q19: No problem with a foreign boss

Q20: No problem with a foreign junior

Q21: No problem with a foreign roommate

Q22: Friends must agree with me

\section{SS5: Exploring Foreign Cultures}

Q23: Desire to travel abroad

Q24: I will be welcome abroad

Q25: Willing to venture into foreign cultures

Q26: Like to have vacation abroad

\section{SS6: Effects of Globalization}

Q27: No need to stop globalization
If I get to know people from other countries and other cultures, I learn that we are more alike than different

I always put efforts to learn from other cultures in one way or other

If I was invited by a foreigner to his house, I will surely follow the invitation

I am most likely to feel good to visit a foreigner

If I were invited by a foreigner to visit, it is likely to be a new learning experience for me

I enjoy eating food of the types originating overseas/from other countries

Getting to know people from another culture is generally fun for me I feel comfortable being around foreigners

I often listen to foreign music for being different and broadening my world view

I do not think my country's dominant cultures represent more values and ethics than many other cultures of the world

I do not think of need for my culture getting better recognition in the world of today to solve many of the problems being faced by the humanity

I do not think there are cultures in the world which may be more superior or more refined than others

I d not think Foreigners living and working in our country are being offered better salaries and more respect than our own people

I would be comfortable with a colleague from a different culture in a superior position to me

I would be comfortable with a colleague from a different culture in an inferior position to me

I would be comfortable with a roommate from another culture

I see It important for me that friends agree with me on most issues

Not like I have no desire to travel abroad

Not like I have no desire to travel abroad because I would feel insecure and unwelcomed amongst people from a different culture

Not like I may never want to move to a new country even if I have better prospects mainly due to the fact that I am unwilling to venture into foreign cultures

If I won a free vacation I would rather spend it in a different country where I am likely to learn about new cultures and ways of life

I do not think Something should be done to stop such damage 
Q28: No cultural damage by globalization

Q29: Immigrants do not steal jobs

Q30: New ideas coming due to globalization

Q31: Can't stop globalization

\section{SS7: Effect of Religion}

Q32: Religion not part of daily life

Q33: No existence of a supernatural power

Q34: Religious Society

Q35: Curious to know other religious thoughts

Q36: No Global problems due to religious beliefs

\section{SS8: Effect of Scapegoating}

Q37: Problem may not increase with foreigners

Q38: No Victimization of foreigners based on their religious beliefs

Q39: Unrelated person never getting randomly targeted

Q40: Rational Society for foreigners

Q41: Irrational behavior of victims blaming a foreigner

Q42: Branded accused without proof

\section{SS9: Effect of liberal society}

Q43: Belief in the theory of evolution

Q44: No problem with a homosexual

Q45: No encounter with persons preaching their religious beliefs

SS10: Using Foreign Products

Q46: Watch foreign movies

Q47: Buy foreign clothing

\section{SS11: Ease of understanding}

Q48: No problem to understand foreigners

Q49: No Repulsion with people of other religion
Globalization of cultures have not damage my cultural, economic and religious traditions in many ways

I do not think Foreigners living and working in our country are stealing away the benefits and privileges from their rightful owners

Globalization has resulted in new ideas and positive cultural influences coming into your country from other countries

Globalization of cultures will happen anyway and cannot be stopped

I do not think religion is a part of my daily life

I do not think there exists a supernatural power which may monitor my activities and perhaps influence me in any way

My native society (read country) is religious

I was curious to know more about his/her religious beliefs

I do not think there are problems in modern world which relates to religious beliefs

Probability of being branded as accused would not increase if the innocent persons also happen to be foreigners

I have never witnessed incidents involving a person of foreign origin persecuted or victimized for his foreign religious belief in my society

There are no insecurities related to sudden turn of events which may result into an unrelated person getting targeted by the society (where I live in) at large

The society (I live in) remains rational in a situation of major crisis involving those which may apparently look like to have been created by certain groups or persons of certain foreign origin or race

In a situation of certain crisis have you witnessed victims behaving irrationally accusing certain group of persons based on their nationality or race?

Do you think there is a possibility of innocent persons been branded as accused without enough proof in your society

I believe in theory of evolution

I have no issues if someone I know has a homosexual orientation

I have never come across some persons preaching me on his religious orientation

I often watch foreign movies because they are windows to different cultures and their ways of life

I like to buy foreign clothing brands because I want to keep up with the global trends in fashion

When dealing with persons of foreign origin I never had difficulty in understanding his or her point of view

It is not difficult for me to feel close to people who have a different religion from mine 
Q50: No difficulty in understanding of I never have any difficulty in understanding of diverse world cultures diverse world cultures

\section{PART 2: (Conditional Sub - scales)}

\section{SS12: Stereotype}

Higher Income Group Views

Q51: Enterprising Below Income

Q52: Below income as Loyal Employees

Q53: Below income as Trustworthy

Lower Income Group Views

Q54: Caring higher income

Q55: Reliable higher income

Q56: Helpful higher income

Men's Views

Q57: More Chores for women

Q58: Women more talkative

Q59: Women likes to be with women

Women's Views

Q60: Caring Men

Q61: Loving Men

Q62: Respecting Men

\section{SS13: Situational Discrimination}

Have you ever had a problem with a foreigner? If yes answer the following questions

Q63: No Problem with countrymen

Q64: Different behavior with countrymen

Q65: Foreigner should be more careful

Q66: Problem related to his origin

Q67: Behavior was expected due to his origin countryman fellow countryman his/her foreign origin while being in my country specific foreign origin
Below average income persons are generally enterprising enough to look forward to a bright rich future

Below average income persons can generally be trusted as loyal employees

Below average income persons can generally be trusted with work given to them for monetary rewards

Above average income persons care about lower income group

Above average income persons can generally be relied on

Above average income persons may be willing to help highly needy lower income group persons with money or other resources

Women should do more house chores than men

Women are more talkative and cannot keep an important family secret for long

Women generally like the company of females more than males

Men generally care enough for the emotions of women

Men generally love the way women want them to be

Men normally respect women and tend to give the first right of way

\section{PART 3: (Demographic Questions - General)}

$\begin{array}{ll}\text { Country of Residence } & \text { Present Country of Residence } \\ \text { Region } & \text { Geographical Region } \\ \text { City of Residence } & \text { Present City of Residence } \\ \text { Age } & \text { Age } \\ \text { Residential Status } & \text { Residential Status } \\ \text { Education Level } & \text { Education Level } \\ \text { Income Level } & \text { Income Level }\end{array}$

Problem may not have occurred if the person happened to be a fellow

I would have behaved differently if the person would have been a

Person should have been more careful in dealing with me, because of

Peculiar behavior of the person was related to his/her foreign origin

His/her behavior was on expected lines in keeping with his/her

Present Country of Residence

Geographical Region

Present City of Residence

Age

Residential Status

Income Level 
Study Population: The sample size was 200 from more than 10 regions, 84 of whom were men and 116 were women, each working for companies having operations in different countries.

All respondents who met the inclusion criteria of the study were working for multinational companies in their respective countries of residence. The inclusion criteria for the study were - all respondent must be well educated, exposed to multi cultural working environment in a multi country organization, and routinely working and interacting with colleagues with origin from several countries.

The method for the data collection was 'filling out online questionnaire', using the above CFC questionnaire, which is supposed to have fully met the requirements of the current study and consisted of the questions of "assessment of the level of comfort of the local cultures with foreign cultures at their work place" and descriptive characteristics.

The likert type five point scale was used to answer all questions. The five different scales were represented with the following answers: Strongly Agree, Agree, Neutral, Disagree and Strongly Disagree. The process of filling out the questionnaires usually took between 15 and 30 minutes each.

The results of the questionnaire survey were tabulated and means were compared for each sub scales. Based on the means country ranks were given on each subscales. These ranks were used to calculate overall rank scores for each country which gives a comparative estimate of each country's level of comfort with foreign cultures

\subsection{Reliability and Validity Assessment of the Questionnaire}

Validity: Initially, the questionnaire, immediately after the design, was submitted to 20 respondents to determine whether the questions were clear, understandable, and in a logical order (face validity). The construct validity of the questionnaire was tested using the appropriate statistical technique in order to determine the structure of the questionnaire, namely the number of sub- scales measured by this questionnaire, and the questions (items) that constitute each sub- scale.

The criterion validity of the questionnaire was not checked, as a gold standard tool for assessment of the level of comfort of local cultures with foreign cultures in Multinational Companies has not been proposed yet.

Reliability: Finally, the internal consistency and the repeatability of each sub-scale derived from the construct validity of the questionnaire were tested using the appropriate statistical tests. In particular, 50 respondents were used in order to assess the repeatability. These respondents completed the questionnaire two times. Between the two measurements there was a period of three to four days.

Base line characteristics: A number of socio- demographic characteristics of respondents who participated were collected. More specifically, following were recorded:

- Sex

- Age of the respondents

- Educational level

- Residence status in their country of stay

- Their relative income level

\subsection{Statistical Analysis}

Evaluation of the validity and reliability of questionnaire: The factor analysis was used to evaluate the construct validity of the CFC questionnaire. The suitability of the data for carrying out such analysis was tested by using the Bartlett sphericity test (see table 5) and the Kaiser-Meyer-Olkin (KMO) statistic test (see table 5B) that evaluates the degree of correlation among the questions included in the questionnaire.

Statistically significant results of the sphericity test indicates that the variance- covariance matrix of the initial questions of the questionnaire is not diagonal (i.e., variables are correlated with each other). Also, values of $\mathrm{KMO}>0.8$ indicate a fairly high correlation and therefore, factor analysis is meaningful. The method of "Maximum likelihood" was used for assessment / extraction of the main factors (Olsson, U., 1979). The criterion of Kaiser (eigenvalue > 1) was used to determine the number of factors derived from the factor analysis. An orthogonal rotation (in this case Varimax) was used to improve the explanatory ability of the factors. Each factor that emerged was interpreted based on the questions that had load value $>0.3$. Evaluation of the internal consistency of the sub-scales for the CFC questionnaire was carried out by calculating the Standardized Cronbach Alpha coefficient and calculating reliability estimates. Cronbach coefficient ranges from 0 - 1. Large Cronbach Alpha values indicate a high consistency of the questions of which the sub-scale is consisted. The "Cronbach Alpha if item deleted" index was used to identify the questions that reduced the internal consistency 
of the questionnaire and therefore had to be excluded. The repeatability of questionnaire was evaluated by using McDonald Omega which is a measure of generalizability of the test items. It varies between 0 to 1 . Omega can be interpreted as the square of the correlation between the scale score and the latent variable common to all the indicators in the infinite universe of indicators of which the scale indicators are a subset (McDonald, 1999, page 89).

The greatest lower bound was calculated for reliability testing. The greatest lower bound (glb) to reliability represents the smallest reliability possible given observed covariance matrix under the restriction that the sum of error variances is maximized for errors that correlate 0 with other variables (Ten Berge, Snijders, \& Zegers, 1981).

All statistical analysis was carried out using SPSS and FACTOR PROGRAM developed by Dr. Urbano Lorenzo-Seva \& Dr. Pere Joan Ferrando, (2012).

\subsection{Calculating the Difference on Level of Comfort with Foreign Cultures}

The questionnaire as validated as per the above method was used to estimate differences among 10 countries by comparing the means of each country on different sub scales.

\section{Analysis and Results}

\subsection{Descriptive Results}

Table 2 presents the baseline characteristics of the participants from 10 regions $(\mathrm{N}=200)$. It was observed that the majority of the participants were in the age group of 30 to 50 years, mostly having post graduate education.

Table 2. Baseline characteristics of region based respondents

\begin{tabular}{|c|c|c|c|c|c|c|c|}
\hline $\begin{array}{l}\text { Name of } \\
\text { Country }\end{array}$ & $\begin{array}{c}\text { No of } \\
\text { Respondents }\end{array}$ & $\begin{array}{c}\text { Average } \\
\text { Age }\end{array}$ & $\begin{array}{c}\text { Median } \\
\text { Age }\end{array}$ & $\begin{array}{l}\text { Residence } \\
\text { Status }\end{array}$ & $\begin{array}{c}\text { Educational } \\
\text { Level }\end{array}$ & $\begin{array}{l}\text { Income } \\
\text { Level }\end{array}$ & Sex \\
\hline Brasil & 18 & 40 & 41 & $\begin{array}{l}\text { Mostly } \\
\text { Natives }\end{array}$ & $\begin{array}{l}\text { Mostly Post } \\
\text { Graduate }\end{array}$ & $\begin{array}{c}\text { Av \& Above } \\
\text { Av }\end{array}$ & $80 \% \mathrm{~F} / 20 \% \mathrm{M}$ \\
\hline USA & 19 & 48 & 49 & $\begin{array}{l}\text { Mostly } \\
\text { Natives or } \\
\text { Estd } \\
\text { Immigrants }\end{array}$ & $\begin{array}{l}\text { Mostly Post } \\
\text { Graduate } \\
\text { /Doctorates }\end{array}$ & Average & $70 \% \mathrm{~F} / 30 \% \mathrm{M}$ \\
\hline India & 28 & 31 & 26 & $\begin{array}{l}\text { Mostly } \\
\text { Natives }\end{array}$ & $\begin{array}{l}\text { Mostly Post } \\
\text { Graduate }\end{array}$ & Average & $45 \% \mathrm{~F} / 55 \% \mathrm{M}$ \\
\hline Italy & 24 & 36 & 35 & $\begin{array}{l}\text { Mostly } \\
\text { Natives }\end{array}$ & $\begin{array}{l}\text { Mostly Post } \\
\text { Graduate } \\
\text { /Doctorates }\end{array}$ & Average & $55 \% \mathrm{~F} / 45 \% \mathrm{M}$ \\
\hline Portugal & 24 & 37 & 36 & $\begin{array}{l}\text { Mostly } \\
\text { Natives }\end{array}$ & $\begin{array}{l}\text { Mostly Post } \\
\text { Graduate }\end{array}$ & $\begin{array}{c}\text { Av \& Above } \\
\text { Av }\end{array}$ & $75 \% \mathrm{~F} / 25 \% \mathrm{M}$ \\
\hline China & 17 & 40 & 39 & $\begin{array}{l}\text { Mostly } \\
\text { Natives }\end{array}$ & $\begin{array}{l}\text { Mostly Post } \\
\text { Graduate }\end{array}$ & $\begin{array}{l}\text { Av \& Above } \\
\text { Average }\end{array}$ & $45 \% \mathrm{~F} / 55 \% \mathrm{M}$ \\
\hline Nigeria & 18 & 42 & 41 & $\begin{array}{l}\text { Mostly } \\
\text { Natives }\end{array}$ & $\begin{array}{l}\text { Mostly Post } \\
\text { Graduate }\end{array}$ & Average & $70 \% \mathrm{~F} / 30 \% \mathrm{M}$ \\
\hline Sweden & 17 & 36 & 37 & $\begin{array}{l}\text { Mostly } \\
\text { Natives }\end{array}$ & $\begin{array}{l}\text { Mostly Post } \\
\text { Graduate }\end{array}$ & $\begin{array}{c}\text { Av \& Above } \\
\text { Av }\end{array}$ & $55 \% \mathrm{~F} / 45 \% \mathrm{M}$ \\
\hline$U K$ & 17 & 46 & 47 & $\begin{array}{l}\text { Mostly } \\
\text { Natives }\end{array}$ & $\begin{array}{l}\text { Mostly Post } \\
\text { Graduate }\end{array}$ & Average & $75 \% \mathrm{~F} / 25 \% \mathrm{M}$ \\
\hline Germany & 18 & 47 & 46 & $\begin{array}{l}\text { Mostly } \\
\text { Natives }\end{array}$ & $\begin{array}{l}\text { Mostly Post } \\
\text { Graduate }\end{array}$ & $\begin{array}{c}\text { Av \& Above } \\
\text { Av }\end{array}$ & $55 \% \mathrm{~F} / 45 \% \mathrm{M}$ \\
\hline Total & 200 & & & $\begin{array}{l}\text { Mostly } \\
\text { Natives }\end{array}$ & $\begin{array}{l}\text { Mostly Post } \\
\text { Graduate }\end{array}$ & $\begin{array}{c}\text { Av \& Above } \\
\text { Av }\end{array}$ & $58 \% \mathrm{~F} / 42 \% \mathrm{M}$ \\
\hline
\end{tabular}


The majority of participants had average or above average income level. Regarding area of residence, most respondents were natives of the country $(90.0 \%)$ where they were interviewed. Regarding distribution by sex, the percentage of female participants $(58.0 \%)$ was significantly higher than the men's percentage $(42.0 \%)$. However country wise sex ratios differed significantly (see table 2). Regarding the socio economic status of sexes, male's percentage in the higher income group (28\%) was significantly higher than females (16\%).

Distribution of participant baseline characteristics is summarized in table 2. It can be seen that country wise distribution of baseline characteristics is not very significantly different from one country to another, indicating the validity of the sample design.

\subsection{Statistic Results}

Regarding face and content validity both participants and experts reported that the questions asked in the questionnaire were clear, easy to understand, in a logical order, and totally representative of the needs of the objectives of the research.

\subsubsection{Construct Validity of the Questionnaire}

As it is already mentioned, factor analysis was performed for the evaluation of the construct validity of the CFC questionnaire. Initially, the relevance of the data used for the factor analysis was confirmed. The statistical criteria Kaiser-Meyer-Olkin $(\mathrm{KMO}=0,948)$ and the Bartlett Test of sphericity (value $15944.3(\mathrm{df}=1275 ; \mathrm{P}=$ $0.000010)$ ), indicated that the raw data were suitable for the implementation of factor analysis. (See table 5 B)

From the 50 original questions used in the factor analysis in general 11 sub - scales as proposed in Delphi session, 40 were confirmed, using the Kaiser criterion and Varimax orthogonal rotation. 10 items were removed from the original version of the questionnaire due to lack of variance and inconsistency in data. See table 3, to see the list of questions removed from the original suggested questionnaire. 2 conditional sub - scales were retained as explained above.

Table 3. List of items removed after empirical testing

\section{PART 1 (General Sub - scales) Full Question}

\section{SS1: Seeing Benefits in Cross Cultures}

Q7: Learn from other cultures

I always put efforts to learn from other cultures in one way or other

\section{SS3: Effect of Patriotism}

Q18: Not like Immigrants getting better salaryI $d$ not think Foreigners living and working in our country are being than us offered better salaries and more respect than our own people

\section{SS4: Effect of Personal Comfort}

Q22: Friends must agree with me

I see It important for me that friends agree with me on most issues

SS6: Effects of Globalization

Globalization has resulted in new ideas and positive cultural

Q30: New ideas coming due to globalization influences coming into your country from other countries Globalization of cultures will happen anyway and cannot be

Q31: Can't stop globalization stopped

\section{SS7: Effect of Religion}

Q34: Religious Society My native society (read country) is religious

Q35: Curious to know other religious thoughtsI was curious to know more about his/her religious beliefs

Q36: No Global problems due to religious I do not think there are problems in modern world which relates to beliefs religious beliefs

\section{SS8: Effect of Scapegoating}

In a situation of certain crisis have you witnessed victims behaving Q41: Irrational behavior of victims blaming a irrationally accusing certain group of persons based on their foreigner nationality or race?

Do you think there is a possibility of innocent persons been branded

Q42: Branded accused without proof as accused without enough proof in your society

Extraction Method: Maximum Likelihood.

Rotation Method: Varimax with Kaiser Normalization 
Table 4 show the factor analysis which confirms the reliability of the questionnaire based on structure of 11 general factors as suggested by the Delphi Sessions. The overall rate of variation of initial data, the 11 factors (Sub-Scales) interpreted in common amounts to $65 \%$ for overall sample of 200 respondents.

Table 4. Factor analysis of responses from 10 countries $(\mathrm{N}=200)$ (Total variance explained $-65 \%)$

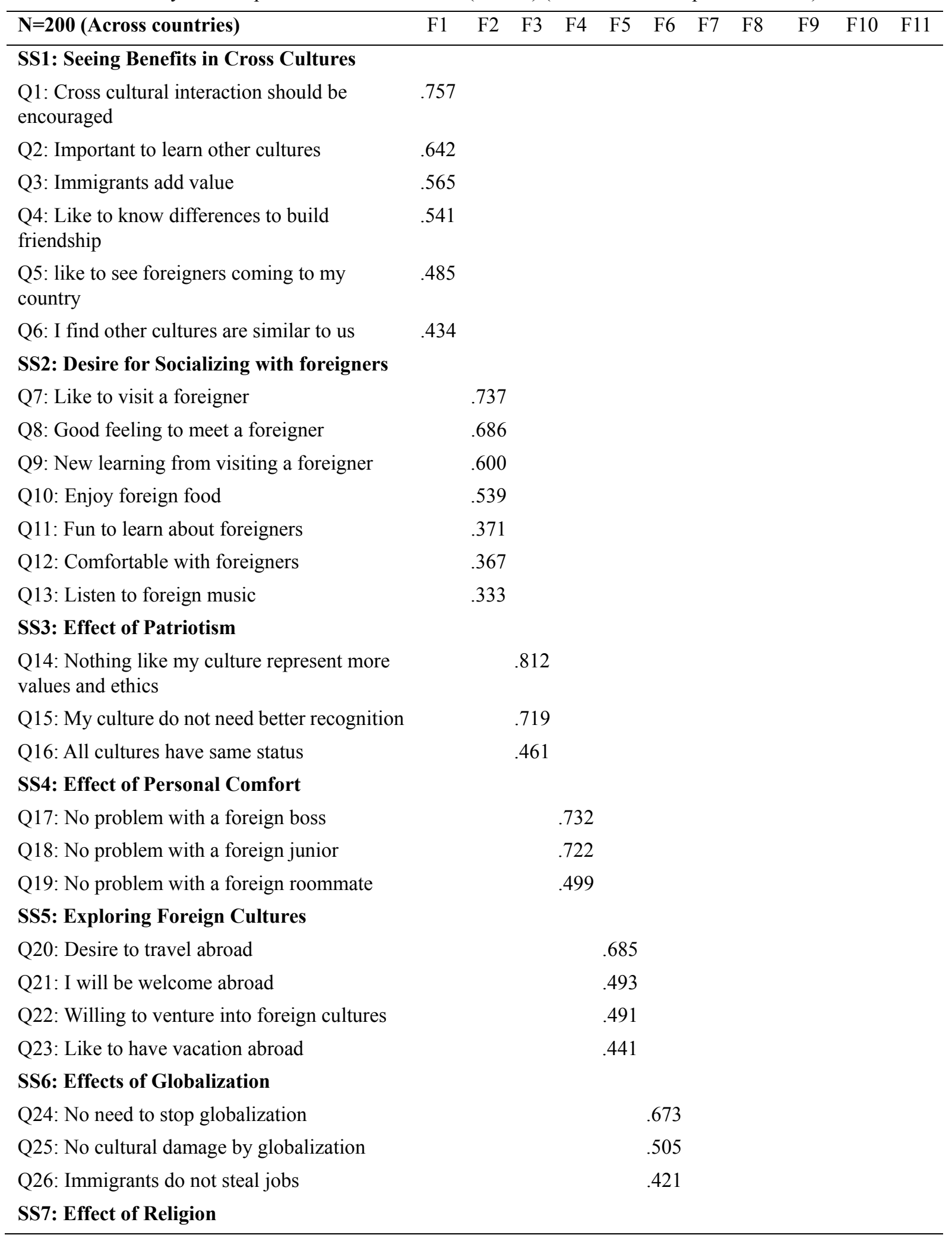


Q27: Religion not part of daily life .742

Q28: No existence of a supernatural power

\section{SS8: Effect of Scapegoating}

Q29: Problem may not increase with foreigners

Q30: No Victimization of foreigners based on

their religious beliefs

Q31: Unrelated person never getting randomly

targeted

Q32: Rational Society for foreigners

\section{SS9: Effect of liberal society}

Q33: Belief in the theory of evolution

Q34: No problem with a homosexual

Q35: No encounter with persons preaching

their religious beliefs

\section{SS10: Using Foreign Products}

Q36: Watch foreign movies

Q37: Buy foreign clothing

\section{SS11: Ease of understanding}

Q38: No problem to understand foreigners

Q39: No Repulsion with people of other religion

Q40: No difficulty in understanding diverse

cultures

Extraction Method: Maximum Likelihood.

Rotation Method: Varimax with Kaiser Normalization

\subsubsection{Evaluation of the Internal Consistency \& Reliability of the Questionnaire}

Table 5A shows the detailed results of the evaluation of the internal consistency and reliability for each sub-scale (factor) of the CFC questionnaire, as those derived from the factor analysis. Table 5A shows that the internal consistency of the questions making up each sub-scale is reasonably high (Most cases $>0.7$ ) except factors 6 and 8. However for subscales values of reliability greater than 0.6 is normally acceptable. The greatest lower bound for reliability is also calculated and has been found to be suitable. (See table 5B)

Table 5A. Explained variance and reliability of rotated factors

\begin{tabular}{ccc}
\hline Sub-Scale (factors) & Variance & Reliability estimate \\
\hline 1 & 4.948 & 0.904 \\
3 & 2.604 & 0.834 \\
4 & 3.564 & 0.875 \\
5 & 1.094 & 0.739 \\
6 & 6.093 & 0.942 \\
7 & 1.031 & 0.685 \\
8 & 1.285 & 0.784 \\
9 & 1.2 & 0.694 \\
10 & 3.634 & 0.861 \\
11 & 1.153 & 0.685 \\
\hline
\end{tabular}

Source: Mislevy \& Bock (1990) 
Table 5B. Other statistics for internal consistency of the CFC questionnaire



Genralizability and repeatability of the questionnaire items has been tested using McDonald Omega which is very good as shown in table $5 \mathrm{~B}$. Also shown are the indices for factor simplicity.

\subsection{Estimate of Differences among Countries with Respect to Comfort with Foreign Culturess}

Following table gives the differences among countries on different sub scales incorporated in the CFC questionnaire and their ranks are also tabulated. Using these ranks total rank score is calculated for each country as given in table. The final rank scores for each country are given.

Table 5C. Summary of statistical analysis for overall sample $(\mathrm{N}=606)$

\begin{tabular}{ll}
\hline Number of participants & $: 200$ \\
Number of variables & $: 50$ \\
Variables included in the analysis & $:$ ALL \\
Variables excluded in the analysis & $:$ NONE \\
Number of factors & $: 11$ \\
Number of second order factors & $:$ Maximum likely hood \\
Method for factor extraction & $:$ Weighted Varimax \\
Clever rotation start & $: 10$ \\
Number of random starts & $: 100$ \\
Maximum member of iterations & $: 0.00001000$ \\
Convergence value & \\
\hline
\end{tabular}

\section{Discussions and Conclusions}

The results support the proposition that above contents and structure of questionnaire proposed may be fairly appropriate for a large scale study on the comfort with foreign cultures (CFC) in multinational enterprises and culturally diverse workplaces around the world. The main sub scales / components which can best describe the 
phenomenon of comfort of local cultures with foreign culture are as follows:

SS1: Seeing Benefits in Cross Cultures

SS2: Desire for Socializing with foreigners

SS3: Effect of Patriotism

SS4: Effect of Personal Comfort

SS5: Exploring Foreign Cultures

SS6: Effects of Globalization

SS7: Effect of Religion

SS8: Effect of Scapegoating

SS9: Effect of liberal society

SS10: Using Foreign Products

SS11: Ease of understanding

SS12: Effect of Stereotype

SS13: Situational Discrimination

The final CFC questionnaire proposed and tested by above study looks as given in table 6. Also given in table 7, 8 and 9 is the rank scores of the countries studied in terms of the level of comfort of the local employees of MNCs with foreign employees.

Table 6. Final proposed CFC questionnaire

\section{PART 1 (General Sub - scales)
SS1: Seeing Benefits in Cross Cultures}

Q1: Cross cultural interaction should be encouraged

\section{Full Question}

Q2: Important to learn other cultures

Q3: Immigrants add value

Interacting with people from different countries should be encouraged because it will help us improve our own values and beliefs

Q4: Like to know differences to build friendship

I think it is important to learn more about other cultures

Q5: like to see foreigners coming to my country

I consider foreign immigration as a value added our country's economy

Knowing how a person differs from me may help me build our friendship

Q6: I find other cultures are similar to us

I would like seeing people from other countries come to my country

If I get to know people from other countries and other cultures, I learn that we are more alike than different

\section{SS2: Desire for Socializing with foreigners}

Q7: Like to visit a foreigner

Q8: Good feeling to meet a foreigner

Q9: New learning from visiting a foreigner

Q10: Enjoy foreign food

Q11: Fun to learn about foreigners

Q12: Comfortable with foreigners

Q13: Listen to foreign music
If I was invited by a foreigner to his house, I will surely follow the invitation

I am most likely to feel good to visit a foreigner

If I were invited by a foreigner to visit, it is likely to be a new learning experience for me

I enjoy eating food of the types originating overseas/from other countries

Getting to know people from another culture is generally fun for me

I feel comfortable being around foreigners

I often listen to foreign music for being different and broadening my world view

\section{SS3: Effect of Patriotism}


Q14: Nothing like my culture represent more values and ethics

Q15: My culture do not need better recognition

Q16: All cultures have same status

\section{SS4: Effect of Personal Comfort}

Q17: No problem with a foreign boss

Q18: No problem with a foreign junior

Q19: No problem with a foreign roommate

\section{SS5: Exploring Foreign Cultures}

Q20: Desire to travel abroad

Q21: I will be welcome abroad

Q22: Willing to venture into foreign cultures

Q23: Like to have vacation abroad

\section{SS6: Effects of Globalization}

Q24: No need to stop globalization

Q25: No cultural damage by globalization

Q26: Immigrants do not steal jobs

\section{SS7: Effect of Religion}

Q27: Religion not part of daily life Q28: No existence of a supernatural power

\section{SS8: Effect of Scapegoating}

Q29: Problem may not increase with foreigners

Q30: No Victimization of foreigners based on their religious beliefs

Q31: Unrelated person never getting randomly targeted

Q32: Rational Society for foreigners

\section{SS9: Effect of liberal society}

Q33: Belief in the theory of evolution

Q34: No problem with a homosexual
I do not think my country's dominant cultures represent more values and ethics than many other cultures of the world

I do not think of need for my culture getting better recognition in the world of today to solve many of the problems being faced by the humanity

I do not think there are cultures in the world which may be more superior or more refined than others

I would be comfortable with a colleague from a different culture in a superior position to me

I would be comfortable with a colleague from a different culture in an inferior position to me

I would be comfortable with a roommate from another culture

Not like I have no desire to travel abroad

Not like I have no desire to travel abroad because I would feel insecure and unwelcomed amongst people from a different culture

Not like I may never want to move to a new country even if I have better prospects mainly due to the fact that I am unwilling to venture into foreign cultures

If I won a free vacation I would rather spend it in a different country where I am likely to learn about new cultures and ways of life

I do not think Something should be done to stop such damage

Globalization of cultures have not damage my cultural, economic and religious traditions in many ways

I do not think Foreigners living and working in our country are stealing away the benefits and privileges from their rightful owners

I do not think religion is a part of my daily life

I do not think there exists a supernatural power which may monitor my activities and perhaps influence me in any way

Probability of being branded as accused would not increase if the innocent persons also happen to be foreigners

I have never witnessed incidents involving a person of foreign origin persecuted or victimized for his foreign religious belief in my society

There are no insecurities related to sudden turn of events which may result into an unrelated person getting targeted by the society (where I live in) at large

The society (I live in) remains rational in a situation of major crisis involving those which may apparently look like to have been created by certain groups or persons of certain foreign origin or race

I believe in theory of evolution

I have no issues if someone I know has a homosexual orientation 
Q35: No encounter with persons preaching their religious beliefs

\section{SS10: Using Foreign Products}

Q36: Watch foreign movies

Q37: Buy foreign clothing

\section{SS11: Ease of understanding}

Q38: No problem to understand foreigners

Q39: No Repulsion with people of other religion

Q40: No Repulsion with people of other religion

\section{PART 2: (Conditional Sub - scales)}

\section{SS12: Effect of Stereotype}

Higher Income Group Views

Q51: Enterprising Below Income

Q52: Below income as Loyal Employees

Q53: Below income as Trustworthy

\section{Lower Income Group Views}

Q54: Caring higher income

Q55: Reliable higher income

Q56: Helpful higher income

\section{Men's Views}

Q57: More Chores for women

Q58: Women more talkative

Q59: Women likes to be with women

Women's Views

Q60: Caring Men

Q61: Loving Men

Q62: Respecting Men

\section{SS13: Situational Discrimination}

Q63: No Problem with countrymen

Q64: Different behavior with countrymen

Q65: Foreigner should be more careful

Q66: Problem related to his origin
I have never come across some persons preaching me on his religious orientation

I often watch foreign movies because they are windows to different cultures and their ways of life

I like to buy foreign clothing brands because I want to keep up with the global trends in fashion

When dealing with persons of foreign origin I never had difficulty in understanding his or her point of view

It is not difficult for me to feel close to people who have a different religion from mine

I never have any difficulty in understanding of diverse world cultures

Below average income persons are generally enterprising enough to look forward to a bright rich future

Below average income persons can generally be trusted as loyal employees

Below average income persons can generally be trusted with work given to them for monetary rewards

Above average income persons care about lower income group

Above average income persons can generally be relied on

Above average income persons may be willing to help highly needy lower income group persons with money or other resources

Women should do more house chores than men

Women are more talkative and cannot keep an important family secret for long

Women generally like the company of females more than males

Men generally care enough for the emotions of women

Men generally love the way women want them to be

Men normally respect women and tend to give the first right of way

Problem may not have occurred if the person happened to be a fellow countryman

I would have behaved differently if the person would have been a fellow countryman

Person should have been more careful in dealing with me, because of his/her foreign origin while being in my country

Peculiar behavior of the person was related to his/her foreign origin 
Q67: Behavior was expected due to his origin

\section{PART 3: (Demographic Questions - General)}

Country of Residence

Region

City of Residence

Age

Residential Status

Education Level

Income Level
Present Country of Residence

Geographical Region

Present City / country of Residence

Age

Residential Status

Education Level

Income Level

Table 7. Ranking of countries

\begin{tabular}{|c|c|c|c|c|c|c|c|c|c|c|}
\hline & Nigeria & China & Germany & India & Italy & LA & Portugal & eden & UK & USA \\
\hline SS1 & 5 & 7 & 8 & 9 & 10 & 2 & 6 & 1 & 4 & 3 \\
\hline $\mathrm{SS} 2$ & 6 & 9 & 7 & 10 & 8 & 1 & 2 & 5 & 3 & 4 \\
\hline $\mathrm{SS} 3$ & 3 & 1 & 7 & 10 & 8 & 9 & 6 & 2 & 5 & 4 \\
\hline SS4 & 7 & 4 & 9 & 10 & 8 & 2 & 3 & 1 & 5 & 6 \\
\hline SS5 & 9 & 2 & 7 & 10 & 8 & 5 & 6 & 1 & 3 & 4 \\
\hline SS6 & 9 & 1 & 7 & 10 & 4 & 6 & 8 & 5 & 3 & 2 \\
\hline SS7 & 10 & 1 & 7 & 9 & 2 & 8 & 6 & 4 & 3 & 5 \\
\hline SS8 & 3 & 4 & 5 & 2 & 6 & 8 & 1 & 10 & 7 & 9 \\
\hline SS9 & 8 & 4 & 3 & 9 & 6 & 10 & 7 & 1 & 2 & 5 \\
\hline SS10 & 6 & 1 & 9 & 3 & 8 & 2 & 4.5 & 10 & 4.5 & 7 \\
\hline SS11 & 3 & 6.5 & 6.5 & 10 & 4 & 2 & 1 & 8 & 5 & 9 \\
\hline $\begin{array}{l}\text { SS12A: Stereotypes among } \\
\text { Higher Income Group }\end{array}$ & 5 & 1 & 9 & 4 & 7 & 6 & 8 & 2 & 3 & 10 \\
\hline $\begin{array}{l}\text { SS12B: Stereotypes among Low } \\
\text { Income Group }\end{array}$ & 3 & 8 & 4 & 2 & 10 & 5 & 1 & 9 & 6 & 7 \\
\hline $\begin{array}{l}\text { SS12C: Stereotypes among } \\
\text { Females }\end{array}$ & 4 & 7 & 6 & 10 & 3 & 9 & 1 & 2 & 5 & 8 \\
\hline SS12D: Stereotypes among Males & 7 & 3 & 9 & 10 & 8 & 2 & 6 & 1 & 5 & 4 \\
\hline $\begin{array}{l}\text { SS13: Reactions to foreigners } \\
\text { during a confrontation }\end{array}$ & 8 & 6 & 3 & 7 & 9 & 10 & 2 & 1 & 4 & 5 \\
\hline Total Rank Scores & 96 & 65.5 & 106.5 & 125 & 109 & 87 & 68.5 & 63 & 68 & 92 \\
\hline $\begin{array}{l}\text { Notional Overall Rank (1) } \\
\text { (based on rank totals) }\end{array}$ & 7 & 2 & 8 & 10 & 9 & 5 & 4 & 1 & 3 & 6 \\
\hline
\end{tabular}

If we calculate the overall mean on CFC based on all sub scales we have the following table 8 . 
Table 8. Overall ranking based on mean score averages

\begin{tabular}{lcccccccccc}
\hline & Nigeria & China & Germany & India & Italy & LA & Portugal & Sweden & UK & USA \\
\hline SS1 & 1.60 & 1.79 & 1.83 & 2.10 & 2.12 & 1.45 & 1.71 & 1.21 & 1.58 & 1.53 \\
SS2 & 1.63 & 1.79 & 1.67 & 2.39 & 1.78 & 1.38 & 1.51 & 1.57 & 1.51 & 1.53 \\
SS3 & 2.25 & 1.92 & 2.57 & 3.67 & 2.52 & 2.64 & 2.43 & 2.00 & 2.39 & 2.37 \\
SS4 & 1.64 & 1.58 & 1.83 & 2.48 & 1.71 & 1.46 & 1.57 & 1.33 & 1.58 & 1.63 \\
SS5 & 1.73 & 1.38 & 1.53 & 2.07 & 1.57 & 1.44 & 1.50 & 1.19 & 1.41 & 1.43 \\
SS6 & 2.72 & 1.92 & 2.40 & 3.05 & 2.24 & 2.36 & 2.48 & 2.25 & 2.21 & 2.03 \\
SS7 & 4.00 & 2.00 & 3.55 & 3.71 & 2.64 & 3.69 & 3.64 & 3.38 & 3.23 & 3.45 \\
SS8 & 2.88 & 3.06 & 3.10 & 2.71 & 3.21 & 3.31 & 2.79 & 3.50 & 3.27 & 3.40 \\
SS9 & 2.58 & 2.25 & 2.23 & 2.81 & 2.43 & 2.82 & 2.48 & 1.92 & 1.94 & 2.27 \\
SS10 & 2.71 & 2.13 & 2.85 & 2.57 & 2.79 & 2.50 & 2.64 & 3.00 & 2.64 & 2.75 \\
SS11 & 1.89 & 2.17 & 2.17 & 2.43 & 1.90 & 1.87 & 1.86 & 2.25 & 2.06 & 2.27 \\
SS12A: Stereotypes among & & & & & & & & & & \\
Higher Income Group & 2.91 & 2.00 & 3.00 & 3.00 & & 3.00 & 2.89 & 2.00 & 2.72 & 3.00 \\
SS12B: Stereotypes among & & & & & & & & & & \\
Low Income Group & 2.80 & 3.11 & 2.83 & 2.67 & 3.09 & 2.81 & 2.75 & 3.11 & 3.08 & 3.04 \\
SS12C: Stereotypes among & & & & & & & & & & \\
Females & 2.67 & 3.56 & 2.92 & 3.67 & 2.44 & 3.70 & 2.17 & 2.44 & 2.90 & 3.71 \\
SS12D: Stereotypes among & & & & & & & & & & \\
Males & 2.70 & 2.33 & 2.83 & 2.89 & 2.67 & 2.00 & 2.44 & 1.33 & 2.58 & 2.17 \\
SS13: Reactions to foreigners & & & & & & & & & & \\
during a confrontation & 3.09 & 2.70 & 2.50 & 3.07 & 2.53 & 3.00 & 2.13 & 2.00 & 2.47 & 2.49 \\
Overall country wise means & 2.49 & 2.23 & 2.49 & 2.83 & 2.38 & 2.47 & 2.31 & 2.15 & 2.35 & 2.44 \\
Notional Overall Rank (2) & & & & & & & & & & \\
(based on overall means) & $\mathbf{8}$ & $\mathbf{2}$ & $\mathbf{9}$ & $\mathbf{1 0}$ & $\mathbf{5}$ & $\mathbf{7}$ & $\mathbf{3}$ & $\mathbf{1}$ & $\mathbf{4}$ & $\mathbf{6}$ \\
\hline & & & & & & & & & \\
& & & & & & & & & &
\end{tabular}

Table 9. Overall national ranks (based on rank totals and overall mean)

\begin{tabular}{lcc}
\hline Country & Rank (1) & Rank (2) \\
\hline Sweden & 1 & 1 \\
China & 2 & 2 \\
UK & 3 & 4 \\
Portugal & 4 & 3 \\
LA & 5 & 7 \\
USA & 6 & 6 \\
Africa & 7 & 8 \\
Europe & 8 & 9 \\
Italy & 9 & 5 \\
India & 10 & 10 \\
\hline
\end{tabular}

\section{Limitations of the Above Results}

While reliability of the above data is quite acceptable in view of several tests done, in the above study, Greatest Lower Bound (GLB) and Omega may not indicate reliability conclusively since GLB and Omega can only be trusted in even large samples, preferably 1,000 cases or more, due to a positive sampling bias (Ten Berge \& 
Socan, 2004). The above study could cover only 606 respondents sue to limitation of resources, therefore a more detailed study involving more than 1000 cases may be more reliable for above testing. Similarly the items of the questionnaire may not represent complete picture of the enquiry and may be subject to change with changing cross cultural environment with time. The above questionnaire therefore may need to be relooked after a reasonable time interval of say every 5 years.

\section{Acknowledgements}

The authors are very thankful to the concerted help given by the management students of I.T.S - Management \& IT Institute, BIMTECH and other B-Schools who took active participation in data collection, data analysis, Delphi sessions etc. Also authors are thankful to several cross cultural experts, professors and industry people who contributed to the paper in different ways during number of brainstorming sessions, seminars and Delphi sessions.

\section{References}

Adair, J. (2003). The Inspirational Leader. London: Kogan-Page.

Bentler, P. M. (1977). Factor simplicity index and transformations. Psychometrika, 59, 567-579.

Chia, R. C., Elmer P., \& Karl, L. W. (2009). Attitude Change after Taking a Virtual Global Understanding Course. International Journal of Human and Social Sciences, 4(2).

De Cieri, H., Dowling, P. J., \& Taylor, K. F. (1991). The psychological impact of expatriate relocation on partners. The International Journal of Human Resource Management, 2(3), 377-414. http://dx.doi.org/10.1080/09585199100000074

Engel, J. F., Blackwell, R. D., \& Miniard, P. W. (1995). Consumer Behavior (8th ed.). Orlando, FL: The Dryden Press.

Hall, E. T. (1976). Beyond Culture. Garden City, NY: Doubleday Anchor Books.

Hofstede, G. (1980). Culture's Consequences: International Differences in Work Related Values. Beverly Hills, CA: Sage Publications.

Hofstede, G. (1991). Cultures and Organizations-Software of the Minds. McGraw-Hill Book Company, London.

Huntington, S. P. (1993). The clash of civilizations? Foreign Affairs, 72(3), 22-49. http://dx.doi.org/10.2307/20045621

Huntington, S. P. (1996). The Clash of Civilizations and the Remaking of World Order. New York: Simon and Schuster.

Lorenzo-Seva, U. (1999). Promin: a method for oblique factor rotation. Multivariate Behavioral Research, 34, 347-356. http://dx.doi.org/10.1207/S15327906MBR3403_3

Lorenzo-Seva, U. (2003). A factor simplicity index. Psychometrika, 68, 49-60. http://dx.doi.org/10.1007/BF02296652

Lorenzo, S., Urbano, L. S., \& Pere Joan F. (2012). Departament de Psicologia, Universitat Rovira i Virgili, Tarragona (Spain), May, 2012.

Manev, I. M., \& Stevenson, W. B. (2001). Nationality, cultural distance, and expatriate status: Effects on the managerial network in a multinational enterprise. Journal of International Business Studies, 32(2), 285-303. http://dx.doi.org/10.1057/palgrave.jibs.8490953

McDonald, R. P. (1999). Test theory: A unified treatment. Mahwah, NJ: Lawrence Erlbaum.

Olsson, U. (1979a). Maximum likelihood estimation of the polychoric correlation coefficient. Psychometrika, 44, 443-460. http://dx.doi.org/10.1007/BF02296207

Olsson, U. (1979b). On the robustness of factor analysis against crude classification of the observations. Multivariate Behavioral Research, 14, 485-500. http://dx.doi.org/10.1207/s15327906mbr1404_7

Paswan, A. K., et al, (2005). Cross-Cultural Interaction Comfort and Service Evaluation. Journal of International Consumer Marketing, 18(1/2).

Ten Berge, J. M. F., \& Socan, G. (2004). The greatest lower bound to the reliability of a test and the hypothesis of unidimensionality. Psychometrika, 69, 613-625. http://dx.doi.org/10.1007/BF02289858

Ten Berge, J. M. F., Snijders, T. A. B., \& Zegers, F. E. (1981). Computational aspects of the greatest lower bound to reliability and constrained minimum trace factor analysis. Psychometrika, 46, 201-213. 
http://dx.doi.org/10.1007/BF02293900

Triandis, H. C. (1994). Culture and Social Behavior. New York, NY: McGraw-Hill.

Triandis, H. C. (2000). Culture and conflict. International Journal of Psychology, 35(2), 145-152. http://dx.doi.org/10.1080/002075900399448

Trompenaars, F. (1994). Riding the Waves of Culture. New York, NY: Irwin.

Valentine, D. (2001). Intercultural business communication, international students, and experiential learning. Business Communication Quarterly, 64(4), 90-104. http://dx.doi.org/10.1177/108056990106400410

Woodhouse, B., \& Jackson, P. H. (1977). Lower bounds to the reliability of the total score on a test composed of no homogeneous items: II. A search procedure to locate the greatest lower bound. Psychometrika, 42, 579-591. http://dx.doi.org/10.1007/BF02295980 